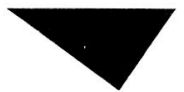

\title{
Obliscência: Por uma Teoria Pós- Moderna da Memória e do Esquecimento
}

\author{
Erick Felinto $^{*}$ \\ Universidade do Estado do Rio de Janeiro
}

Resumo: A pós-modernidade

alçou o esquecimento à condição de una arte. Cultura do efêmero, da desaparição da memória, o pósmoderno necessita de uma teoria da memória capaz de fundamentar a centralidade do esquecimento. Este artigo expõe e comenta as teorias de Geoffrey Sonnabend como modelo para uma arte pós-moderna do oblívio.
Abstract: Postmodern culture and aesthetics have promoted oblivion to an art form. Postmodernism is thus characterized by the disintegration of memory, by a taste for the impermanent, and as such it requires a theory of forgetting capable of justifying the importance of forgetfulness. This article presents and comments on Geoffrey. Sonnabend's theories as a paradigm for a postmodern art of oblivion.

\footnotetext{
* Mestre em Teoria da Comunicação pela ECO/UFRJ, Doutor em Literatura Comparada pela UERJ e Ph.D. candidate em Linguística e Literaturas Românicas pela Universidade da Califórnia, Los Angeles (UCLA). Desenvolve pesquisas em torno das relações entre religiosidade, comunicação e filosofia na pós-modernidade para o Mestrado em Comunicação da FCS/UERJ, onde é professor adjunto.
} 
Et si je suis homme de quelque leçon, je suis homme de nulle retention", Montaigne, Essais, II, X, $177(I: 84)$

\section{Breve Genealogia do Esquecimento}

Montaigne aludiu tantas vezes à incompetência de sua memória e com freqüência em um tom antes celebratório que lamuriante - que não custaria imaginar nessa insistência certo elogio do esquecimento. Uma das passagens dos Essais parece confirmar tal idéia com a afirmativa de que a evocação de obras e o uso de citações arriscam contaminar o estilo do autor. No ato de escrever, Montaigne repele a companhia dos livros já lidos, "de peur qu'ils n'interropent ma forme" (III, 5, 852b). Seguindo esse raciocínio, Antoine Compagnon chega a definir os Essais como resultado dos problemas de memória de Montaigne, como uma "amnésia feliz" (1979: 299). Numa época em que o apelo à autoridade da tradição e sua memória reinava soberano, o texto de Montaigne oferecia uma abordagem surpreendente ${ }^{1}$. Não seria assim, porém, no âmbito de um horizonte cultural pósmoderno.

De fato, um dos traços mais intrigantes da estética e da visão de mundo pós-modernas pode ser definido precisamente como uma poetização (e potencialização) do esquecimento. O esquecimento assume um papel programático, estético, ativo e nietzscheano: esquecer torna-se uma arte que o homem precisa aprender com os animais, morrendo e renascendo a cada instante, verdadeiros seres anhistóricos (unhistorisch), libertos de todo passado, como se explica nas Considerações Intempestivas (1955: 102). A pósmodernidade elevou essa noção a um preceito estético e, nesse sentido, Montaigne e Nietzsche aparecem como precursores importantes $^{2}$. Do esquecimento involuntário, indesejado, passa-se, sob os auspícios dos dois pensadores, à derrota consciente da lembrança, ao desejo de esquecimento.

Mas o esquecimento tradicionalmente constituiu a contraparte perversa da memória, a destruição que ocorria por força do tempo e das distorções imprevisíveis da mente humana. Como chegou, então, a converter-se de malfeitor a herói da história? Essa passagem gradual fez-se em diversas etapas das quais podemos apenas apontar os momentos mais significativos. Ao submeter o material mnemônico à ação da condensação e deformação, e configurar o olvido como manifestação da vida psíquica, Freud foi também um pre- 
cursor na reversão do papel do esquecimento. Na Psicopatologia da Vida Cotidiana, esquecer caracteriza-se como uma atividade produtiva. "Lapsos, erros de escrita e de leitura, esquecimento de impressões e projetos, mal entendidos, desorientação, falsos reconhecimentos - tudo isso resulta da interferência de duas intenções onde uma é manifesta, a outra, reprimida e, por isso mesmo, geradora de desordem" (Robert, 1964: 242). Como explica Marthe Robert, em Freud o esquecimento adquire uma condição produtiva. Em sua aparente casualidade, é preciso desvelar alguma intenção não evidente.

A primazia do esquecimento veio consolidar-se com a difusão das novas tecnologias de comunicação massiva. Umberto Eco foi preciso ao identificar duas características fundamentais dos mass media: eles são simultaneamente genealógicos e desmemoriados, ainda que os dois traços aparentem ser incompatíveis. "São genealógicos porque neles toda invenção produz imitações em cadeia, produz uma espécie de linguagem comum. Não têm memória porque, depois que se produziu a cadeia de imitações, ninguém mais pode se lembrar quem a iniciou e se confunde facilmente o iniciador da estirpe com o último dos netos" (1984: 176). Mas a questão é ainda mais complexa. Não há domínio da existência contemporânea que não seja contaminado pela paixão do apagamento. Nada dura, nada permanece. Tudo evapora-se, desmancha-se no ar sob o patrocínio fundamental desses meios, para os quais a efemeridade é necessidade intrínseca. Nesse sentido, Baudrillard chega a falar em uma diluição midiática da história como evento. Tudo se 'historicizou', de modo que a noção perdeu seu poder, sua validade transcendental (1998: 8). Sofremos de um excesso de história, de um excesso de interpretação que, paradoxalmente, lançam a cultura pós-moderna em um vazio absoluto. "A história hoje é demasiado real e demasiado imediata, à medida que os eventos que deveriam constituí-la não têm tempo de desenvolver-se fora dos meios de comunicação. O estreitamento da história aos 'eventos correntes' transforma a história no 'tempo real' do noticiário", explica Christopher Horrocks ao comentar as idéias de Baudrillard (1999; 26). Esta é a época do esquecimento absoluto e supremo. Época que, paradoxalmente, desenvolveu os mais sofisticados meios e recursos técnicos para a preservação da informação.

A biblioteca medieval de $O$ Nome da Rosa estruturava-se segundo padrões mnemônicos. Os corredores, salas e estantes reproduziam microcosmicamente a geografia do mundo conhecido. O conhecimento inteiro cabia, então, no espaço limitado daqueles corredores e hexágonos, e sua forma de organização podia ser inteiramente domi- 
nada pela memória humana. Era um "palácio da memória", organizado exatamente como uma daquelas construções mentais que o Jesuíta Matteo Ricci empregara, no século XVII, para memorizar os ideogramas chineses ${ }^{3}$. Hoje, o conhecimento cabe apenas no espaço virtual, hiperdimensional, das redes de computadores, e escapa inteiramente das possibilidades da memória. Se por um lado, as tecnologias digitais permitem o desenvolvimento de uma memória maquinal perfeita, na esfera da experiência humana esquecimento e seleção tornaram-se, mais que nunca, vitais.

Tornamo-nos "pós-humanos", em uma situação na qual a 24 materialidade corpórea já não é mais vista como sustentáculo da consciência, da memória e da individualidade (Hayles, 1999: 1-24). Cientistas como Hans Moravec já sugerem que a identidade humana é constituída por padrões informacionais antes que por uma atuação corporal, e desse modo chega-se a imaginar a possibilidade de "transferir" (download) consciências e memórias humanas para cérebros maquínicos (Wertheim, 1999: 21). Em um tal contexto, tornase de fato necessário repensar o papel da memória (bem como do esquecimento) na constituição das experiências humanas. Nossa cultura produziu uma estetização do esquecimento. Cumpre agora encontrar uma teoria do oblívio.

\section{A "Memória Verdadeira"}

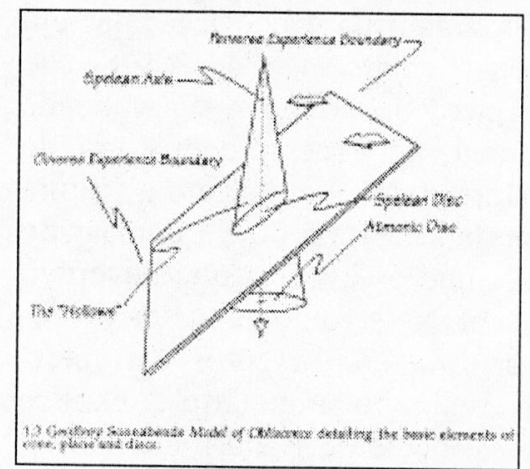

O grande neurologista norteamericano Geoffrey Sonnabend jamais se esqueceria daquela noite de 1936 quando, após assistir a um concerto da solista Madelena Delani em Foz do Iguaçu, viu-se tomado de impiedosa insônia. Inspirado pela extraordinária voz de Delani, Sonnabend retornou para seu quarto de hotel e uma sucessão de idéias e teorias tomou de assalto seu cérebro. Filho de um engenheiro alemão e de uma dama argentina da alta burguesia, Geoffrey conhecia bastante bem a região: fora lá que seus pais haviam se conhecido e lá também que Wilhelm Sonnabend, o jo- 
vem engenheiro, vira desmoronar sua monumental tentativa de construir uma ponte suspensa sobre as Quedas de Iguaçu. Contudo, naquela noite o cenário familiar converteu-se em exótico pano de fundo de acontecimentos extraordinários. Nela, Geoffrey elaborou de um só golpe os principais fundamentos da alentada obra que iria publicar em três volumes dez anos depois, nos EUA, Obliscence: Theories of Forgetting and the Problem of Mattert.

A contribuição mais original do trabalho de Sonnabend era a afirmativa de que o esquecimento, e não a lembrança, constituía o inevitável resultado de toda experiência. A passagem onde Sonnabend descreve a precedência do esquecimento sobre a existência humana é memorável:

Nós, amnésicos todos, condenados a viver em um presente eternamente fugidio, criamos a mais elaborada das construções humanas para proteger-nos contra o intolerável consciência da irreversível passagem do tempo e do irrecuperável caráter de seus momentos e eventos (apud Worth, 1991: 3).

A percepção de que o tempo caminha sem cessar e todo evento é fugaz produz uma sensação de angústia que só pode ser compensada pelas representações da memória. "We, amnesiacs all...": Na década em que Sonnabend elaborava essa frase, Walter Benjamin descrevia, no ensaio der Erzähler (1936), a aparência dos que vinham dos campos de batalha ao término da Primeira Guerra Mundial. Homens que retornavam emudecidos (verstummt), incapazes de narrar, incapazes de experiência autêntica (Erfahrung) c, portanto, de memória narrativa (1991: 439). Usando a guerra como marco simbólico. Benjamin lançava mão das teses de Proust sobre as memórias voluntária e involuntária assim como, algo equivocadamente, das idéias de Freud sobre as relações entre memória e consciência para narrar a decadência da experiência ${ }^{5}$. Naquele momento e nos anos posteriores, de fato, desenrolava-se uma etapa importante no desenvolvimento de nossa amnésia contemporânea. Percorrendo os desolados cenários europeus logo após a Segunda Guerra Mundial, o filósofo Max Picard descreve um estado de coisas que parece repetir ou intensificar o choque identificado por Benjamin anteriormente:

Ao retornar à cidade, observo os homens. Quase todas as faces encontram-se vazias, uniformemente vazias; um tipo de vazio comum nascera; é como se esse vazio tivesse sido precedido por um acontecimento terrível, por algo como uma nova queda, uma queda menor, inútil, minável, que traz aos homens não a morte que cerra a vida por meio de um fim, mas a morte que se instala na vida e, por um trabalho incessante e silencioso, nela penetra e a esvazia. Todos 
se esvaziam; logo não se percebe o que se passou. Mas essa degradação imperceptível e contínua em seu ser interior torna os homens inquietos e nervosos (1957: 3).

Porém, para Sonnabend, que desenvolve suas teorias entre as duas grandes guerras, a amnésia é nossa condição natural, e, em conseqüência, também o é a incapacidade de narrar verdadeiramente os eventos passados. Os eventos traumáticos da história poderiam, assim, apenas potencializar o que já constitui uma situação inata aos mecanismos mentais do homem. O esquecimento está na essência da vida humana. Não é que a experiência da memória inexista. Pelo contrário, ela é bastante "real", todavia consiste na verdade em construções artificiais e intencionais (confabulations), erigidas em torno de partículas das vivências retidas. A imaginação interfere, assim, de maneira vital na constituição da memória. Mais que reprodução, a memória é uma criação ${ }^{6}$.

O radicalismo de Sonnabend levou-o a criticar tanto a memória de curto prazo como a de longo prazo. "Só existe a experiência e seu declínio", assegurou (apud Worth, 1991: 4). A memória de curto prazo não é, em sentido estrito, memória alguma, mas simplesmente a vivência do declínio das percepções e experiências. Contudo, dado que a memória de longo prazo não passa de ilusão, confabulação, a recordação de curto prazo acaba por constituir nossa única conexão com o passado. É à tentativa de explicar o funcionamento dessa falsa memória, denominada paradoxalmente de "true memory" (memória verdadeira), que Sonnabend dedica algumas das páginas mais interessantes de sua obra. A memória verdadeira era descrita por uma série de diagramas, em um elaborado modelo da "obliscência" (obliscence), consistindo basicamente nas figuras de um cone e um plano que se intersectam. É possível que Sonnabend tenha encontrado inspiração para tais diagramas na leitura de Bergson. Em Matière et Mémoire (1896), o filósofo utiliza esquemas com cones e planos para ilustrar as relações entre a totalidade das recordações acumuladas na memória (cone) e a representação mental do mundo circundante (plano) (1963: 293 e 302). É preciso que se diga, porém, que as analogias entre eles limitam-se à escolha das formas. Em Sonnabend, o "cone da obliscência" representa inversamente a ação do esquecimento, ao passo que o "plano da experiência" simboliza o processo da percepção.

Todas as coisas vivas são dotadas de um cone de obliscência (com formatos relativamente variáveis, como se dá com os órgãos de cada indivíduo), por meio do qual toda experiência torna-se efetivamente possível. Sonnabend sugere que pensemos na experiência 
como um plano que se move em direção ao cone da obliscência. Os planos de experiência estão em constante movimento, sempre dirigindo-se da "fronteira obversa da experiência" para a "fronteira perversa da experiência". A passagem do plano através do cone gcra três momentos distintos, que podem ser descritos como: 1) estar envolvido em uma experiência; 2) lembrar uma experiência; 3) ter esquecido uma experiência. O cruzamento de plano e cone geram, assim, a figura de um disco que vai progressivamente diminuindo até desaparecer - "em outras palavras, a experiência passa e a memória vai apagando-se" (apud Worth, 1991: 6).

Um aspecto bastante curioso das teorias de Sonnabend é sua interpretação de fenômenos como a premonição e o dejà-1:u. Sonnabend construiu diversos modelos de possibilidade de intersecção de planos e cones, em um dos quais, por exemplo, o plano toca primeiramente nos vazios do cone em lugar de sua base (o "disco atmônico"), em uma situação inversa ao que normalmente se dá. Se a base do cone representa o campo da consciência imediata do indivíduo, seu vazio figura a região associada à sensação da memória. Desse modo, tem-se a impressão de vivenciar uma experiência pré-lembrada ou intuída - o que chamamos de dejà-vut

Desse breve apanhado das complexas idéias de Sonnabend, ressalta o aspecto produtivo que o cientista conferiu à atividade da memória. Lembrar-se é. na verdade, esquecer e produzir, recriar a experiência passada. A imaginação mescla-se, portanto. ao ato de recordar. Ato que, por sua vez, não passa, no fim das contas, do inevitável processo de declínio da experiência, do esquecimento. Em um contexto pós-moderno, é fácil perceber a rentabilidade de uma teoria como a de Sonnabend. Basta pensar, por exemplo, na estética da citação e da cópia que caracteriza boa parte da produção literária contemporânea. Antoigne Compagnon descreve o processo de leitura como "uma operação inicial de depredação e de apropriação de um objeto que o dispõe à recordação e à imitação, ou seja, à citação. (Repetição, memória, imitação: uma constelação semântica onde convém localizar o lugar da citação)" (1979: 18). Mas aqui trata-se de uma memória traiçoeira ("memória verdadeira" para Sonnabend), daquela que, na verdade, consiste apenas em partículas de vivências (leituras) retidas, reelaboradas pelo processo de recordação-esquecimento. Esquecer-se do que foi lido, produzir um ato intencional de traição, recriação, é condição fundamental. Em um autor como Borges, essa era, de fato, uma das premissas essenciais do processo criador. Como explica Bluma Waddignton Vilar em relação à poética do argentino, 
A possibilidade de se apropriar do modelo por uma transformação radical existe apenas quando a lembrança é falha, quando a memória se retira, dando lugar à imaginação, deixando espaço para a invenção. Esquecer é condição necessária à criação, na medida em que põe em movimento esse processo de preencher hiatos, de repovoar regiões desertadas pela memória (1998: 224).

Sob vários aspectos, esquecer constitui nosso destino inevitável. Onde o passado se acumula em ruínas infinitas e o cansaço com a história torna-se insuportável, o apagamento da memória é uma necessidade. Onde novas tecnologias submetem a cultura a uma acumulação incompreensível de conhecimento ao mesmo tempo em que oferecem os meios de preservar essa ilimitada informação, a obliteração da lembrança humana é requisito absoluto.

\section{A Farsa}

A história de Geoffrey Sonnabend e sua obra é contada em detalhes no pequeno Museum of Jurassic Technology, em Los Angeles? Os visitantes podem inclusive adquirir um pequeno panfleto, de autoria de Valentine Worth, onde se sumarizam as teorias do cientista, com seus fascinantes diagramas de cones de obliscência e planos de experiência. $O$ texto do panfleto encerra-se com uma nota aparentemente inocente:

Essa discussão teve como propósito apenas esboçar em linhas muito gerais a obra extraordinariamente detalhada e abrangente de Geoffrey Sonnabend. Um estudo mais completo e detalhado da obra de Sonnabend oferece a seu estudante ricas recompensas, bem como muitas surpresas (Worth, 1991: 8).

A maior de todas as "surpresas", contudo, seria a descoberta de que Geoffrey Sonnabend e seu monumental Obliscence: Theories of Forgetting and the Problem of Matter não passam de produtos da imaginação do criador do museu, David Wilson. A exposição sobre Sonnabend, cuidadosa e detalhada, é uma brincadeira, um prank, no melhor estilo das invenções de Jorge Luis Borges. Isso não compromete, porém, o valor das teorias de Sonnabend para a compreensão das intrincadas relações entre memória e esquecimento na estética e na Weltanschauung pós-modernas. Pelo contrário, as idéias de Sonnabend constituem um exemplo magistral da aplicação do princípio do esquecimento produtivo. Sonnabend - assim como muitas outras exibições do Museu da Tecnologia Jurássica - surgiu da combinação entre fragmentos de memória (citações), experiências e percepções reais e o trabalho da imaginação. Para engendrar a figura de Sonnabend, David Wilson teve provavelmente de "esquecer" inúme- 
ros textos, referências e indivíduos. Confesso que prazeirosamente me vi envolvido na charada do sr. Wilson. Por quase três anos, tentei, sem sucesso obter as recompensas que o panfleto do museu oferece aos incautos e dedicados investigadores da obra de Sonnabend. A tentativa de encontrar os três volumes da opus magna do cientista absorveu boa parte de minha disposição e recursós mentais durante esse longo período de tempo. Eles tornaram-se. para mim. como o Zahir borgiano: aquele objeto - mapa, moeda, livro - que se engasta na memória de maneira obsessiva e inapagável. Uma vez visto (no meu caso, apenas imaginado), o Zahir não pode jamais ser esquecido e o pobre sujeito que o contemplara vê-se dominado, assim, por uma única imagem pelo resto de sua vida.

No contexto de um ensaio sobre o esquecimento pós-moderno. essa lembrança indelével pode parecer um paradoxo. Entre as explicações que encontro para ela está precisamente o caráter misto da experiência: simulacro e "realidade", memória e esquecimento, invenção e citação combinam-se ali de modo inextricável. Sonnabend permanece uma memória viva para pelo menos um indivíduo (e possivelmente para alguns outros de seus infelizes investigadores), mas trata-se, antes de tudo, de uma memória falsificada, de uma recordação essencialmente inexistente. No fluxo interminável e transitório da vida pós-moderna, uma vida desprovida de experiência autêntica. é apenas natural que essa recordação também venha desaparecer e ser substituida por outra obsessão temporária. Talvez o maior perigo da vivência pós-moderna esteja exatamente em um esquecimento potencializado ao grau máximo. O cansaço com a história produziu os livros que se repetem infindavelmente, citações que circulam sem termo final. Todas as histórias já foram contadas, afirma Eco. Agora restaria apenas recontá-las. Mas sempre há o perigo de um novo cansaço: a exaustão da repetição. do gosto pela paródia, pelo jogo e pelo esquecimento intencional. É possível que também o pós-moderno e suas estratégias da memória e do esquecimento acabem. também, no fim das contas. sendo esquecidos.

\section{Notas}

1. Uma das facetas mais significativas do poder da tradição na Renascença e no Barroco era precisamente a ars memorativa, a "arte da memória", conjunto de técnicas mnemônicas artificiais inventadas supostamente no mundo grego e largamente utilizadas pelos intelectuais nos séculos XVI e XVII. Cf. Yates. Frances. El arte de la memoria (1974). 
2 Sobre a extensão do papel de Nietzsche na formação de uma cultura pós-moderna ou "pós-contemporânea", ver o interessante trabalho de Geoff Waite. Nietzsche's Corps/e: Aesthetics, Politics, Prophecy, or, the Spectacular Technoculture of Everyday Life (1996).

3 A história de Matteo Ricci é contada pelo historiador Johnathan Spence. Em 1583, Ricci chegava à China como missionário. Tentou impressionar seus anfitriões com a apresentação da "arte da memória" que havia diligentemente aprendido no Colégio Jesuíta de Roma. Na maioria das vezes, porém, os chineses não demonstravam grande interesse pela técnica. Cf. Spence, Jonathan D. O Palácio da Memória de Matteo Ricci, 1990.

4 Sonnabend, G. Obliscence: Theories of Forgetting and the Problem of Matter. Chicago: Nothwestern University Press, 1946.

5 Proust fora uma influência importante também para Sonnabend. Sobre os equívocos de Benjamin na interpretação de Freud, ver Rouanet (1990: 73 e ss.)

6 De maneira mais modesta, porém em nítida convergência com a tese de Sonnabend, o psiquiatra Julian Jaynes sugere, em seu polêmico The Origin of Consciousness in the Breakdown of the Bicameral Mind, que largas porções de imagens criadas são introduzidas em nossa memória, um processo descrito por ele com o termo narratizing. "A memória", afirma Jaynes, "é o medium do que-deve-ter-sido" (Memory is the medium of the must-have-been) (1990: 30), pois encena não as coisas como realmente se passaram, mas como devem (ou deveriam) ter se passado de acordo com nossas idealizações.

7 Sobre o Museu da Tecnologia Jurássica, ver o fascinante livro de David Weschler. Mr. Wilson's Cabinet of Wonder (1995).

\section{Bibliografia}

BAUDRILLARD, Jean. Paroxysm: Interviews with Philippe Petit. London: Verso, 1998.

BENJAMIN, Walter. Gesammelte Schriften (Band II.2). Frankfurt: Suhrkamp, 1991.

BERGSON, Henri. Oeuvres. Paris: PUF, 1963. 
COMPAGNON, Antoine. La Seconde Main, ou le Travail de la Citation. Paris: Seuil, 1979.

ECO, Umberto. Viagem na Irrealidade Cotidiana. Rio de Janeiro: Nova Fronteira, 1984.

HAYLES, N. Katherine. How we Became Posthuman: Virtual Bodies in Cybernetics, Literature and Informatics. Chicago: The University of Chicago Press, 1999.

HORROCKS, Christopher. Baudrillard and the Millenium. Cambridge: Icon Books, 1999.

JAYNES, Julian. The Origin of Consciousness in the Breakdown of the Bicameral Mind. Boston: Houghton Mifflin, 1990.

MONTAIGNE, Michel de. Essais. Paris: Garnier, 1958.

NIETZSCHE, Friedrich. Unzeitgemësse Betrachtungen. Stuttgart: Alfred Kröner, 1955.

PICARD, Max. Des Cités Détruites an Monde Inaltérable. Paris: Plon, 1957.

ROBERT, Marthe. La Révolution Psychanalitique I. Paris: Payot, 1964.

ROUANET, Sérgio Paulo. Édipo e o Anjo: Itinerários Freudianos em Walter Benjamin. Rio de Janeiro: Tempo Brasileiro, 1990.

SPENCE, Jonathan D. O Palácio da Memória de Matteo Ricci. São Paulo: Círculo do Livro, 1990.

VILAR, Bluma Waddington. "Elefantes não Escrevem", em CASTRO ROCHA, João Cezar de. Interseções: a Materialidade da Comunicação. Rio de Janeiro: Imago/UERJ, 1998.

YATES, Frances. El arte de la memoria. Madrid: Taurus, 1974.

WAITE, Geoff. Nietzsche's Corps/e: Aesthetics, Politics, Prophecy. or, the Spectacular Technoculture of Everyday Life. Durham: Duke University Press, 1996.

WERTHEIM, Margaret. The Pearly Gates of Cyberspace: a History of Space from Dante to the Internet. New York: W.W. Norton \& Company, 1999.

WESCHLER, Lawrence. Mr. Wilson's Cabinet of Wonder: Pronged Ants, Horned Humans, Mice on Toast, and other Marvels of Jurassic Technology. New York: Vintage Books, 1995. 
WORTH, Valentine. Geoffrey Sonnabend, Obliscence: Theories of Forgetting and the Problem of Matter (an Encapsulation). Los Angeles: Contributions from the Museum of Jurassic Technology, 1991.

Palavras-chave

1. memória;

2. esquecimento;

3. pós-modernidade;

4. Geoffrey Sonnabend;

5. Efêmero 